\title{
VALIDATION OF A FLEXIBLE CONTROLLER FOR A SUPERCONDUCTING GENERATOR
}

\author{
G. A. MORSY \\ Dept. of Elect.Eng., Faculty of Eng., Menoufya Univ., Egypt.
}

\begin{abstract}
This paper describes an improved version of the $\mathrm{H} \infty$ control schemes to enhance the performance and stability of the superconducting generator (SCG). A Flexible control structure is proposed, designed and implemented to overcome the problems that resulting from the low inherent damping nature of the superconducting generator. The controller is implemented using a detailed nonlinear simulation. The timeinvariant state space model is also obtained and the system oscillatory modes are given. The simulation results are represented in comparison with other results which obtained using conventional control systems. The linear time response simulation and the non-linear time response with the transient stability analysis confirms the superiority of the proposed controller and illustrate its effectiveness in system stabilization.
\end{abstract}

\section{1- INTRODUCTION}

Power systems face instability problems or poorly damped electromechanical modes in the range of $.02 \mathrm{~Hz}$ to $2.5 \mathrm{~Hz}[1,2]$. As oscillations of small magnitude and low frequency often persisted for long periods of time and in some cases presented limitations on power transfer capability. Power system control techniques have been implemented to improve system performance and to extend power transfer stability limits. This accomplished via the positive damping that sueh techniques and methodology add to the system modes of oscillation. Many studies have been done in order to improve the dynamic and transient stability of power systems. These include the design of conventional PSSs, static Vars compensators, series condensers and multi-variable controllers etc [3,4]. More

Manuscript received from Dr. G. A. Morsy

Accepted on: 27/3/2002

Engineering Research Journal Vol 25, No 2, 2002 Minufiya University, Faculty of Engineering, Shebien El-Kom, Egypt, ISSN 1110-1180 
ICuem, tue nw and the nuzzy rule based controllers are winning substantial credits [5-7]. Some authers, however, thought that the range of the instability mode should be treated very carefully via different control channels [9]. Therefore, the heuristic design approach proposed in [1] achieves the conflicting goals of providing damping torques at both high and low frequencies. An improved version of that control structure, called " flexible controller " or the $\mathrm{H} \infty$ controller. The flexible controller can be seen as an increased order robust controller [8], since it is a sum of differential lead-lag filters each of them aimed at damping a specific frequency band [9]. Although many tuning procedures have been developed for PSS and other conventional control schemes, most of them not to be suitable for the design of the flexible controller. The SCGs are expected to be the optimum choice among ac generation systems in the future, because of their reduced size, weight, high efficiency, higher generator terminal voltage and its contribution to stability of power systems. However, SCGs have a complex structure and require materials different from those normally used in conventional machines. At the same time these machines are characterized by their low inertia and low inherent damping owing to the interactions between their two electrothermal and damper shields. So, the SCGs requires special attention and consideration. Moreover, the very long field winding time constant make the achievement of acceptable dynamic performance very difficult using excitation control. Therefore, it is necessary to consider only the governor control loop. Various types of controllers were developed to enhance the performance of that complex structure machine, such as phase advance networks, self tuning controller, proportional plus integral controller and neural networks $[10,11]$.

This paper presents the design and implementation procedures of a flexible control scheme to improve the performance of the SCG. After the problem formulation, the modal performance measure were presented taking into consideration the aamping ratios of the oscillation modes. This criteria is applied to design a flexible controller. The linear and non-linear simulation results illustrates the robustness of the controller structure to enhance the system performance and stability.

\section{2-SYSTEM MODEL}

The power system model considered in this study is shown in Fig.(1). It consists of a superconducting generator connected to an infinite bus bar. The generator is driven by a three-stage steam turbine with reheat and fast acting electro-hydraulic governor. A selection switch has been used to consider the control action. The dynamic behavior of this system is governed by fifteen (15) differential equations, seven of which belong to the SCG itself (including two damper windings in each axes), two describe the mechanical torque and the remaining six describe the turbine stages and the electro-hydraulic governor. The system state equations and parameters are given in the appendix. 


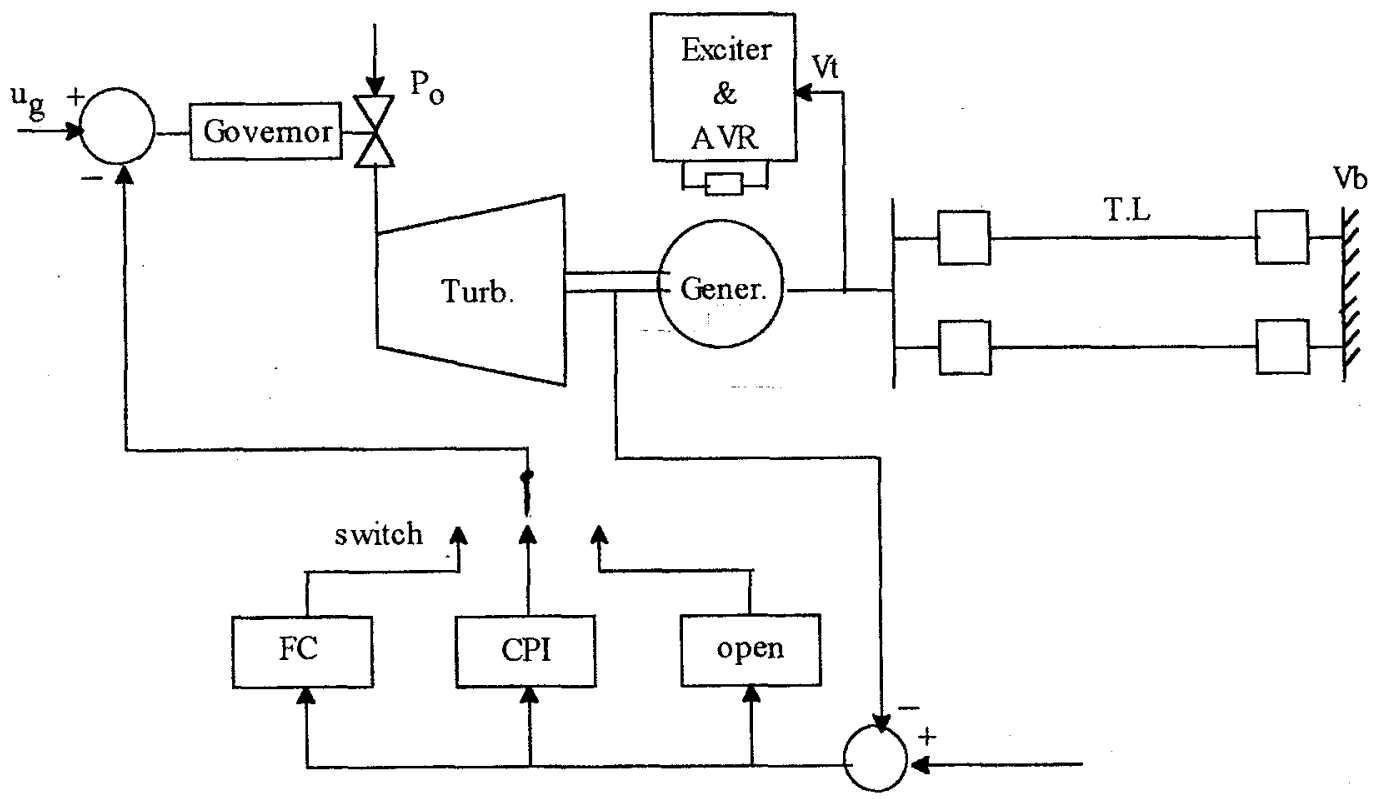

Fig.(1) Schematic diagram of a power system under study with different control scheme

\section{3- CONTROL STRUCTURE AND PROBLEM FORMULATION}

The control objective for SCGs is to generate a stabilizing signal, which is added to the governor loop, in order to enhance the damping of the rotor oscillations after disturbances and consequently improve both the transient and dynamic performance of the system. The flexible controller is a high order controller, whose time constants are chosen in order to damp out specific ranges of modes. It consists of three frequency bands each of them contain two multistage control channels. Considering the general definition given in [9] and the system shown in Fig. (2), the controller can be defined as follows [12] :

$$
\mathrm{H}(\mathrm{s})=\mathrm{K}\left\{\mathrm{K}_{\mathrm{If}} \mathrm{H}_{\mathrm{lf}}(\mathrm{s})+\mathrm{K}_{\mathrm{if}} \mathrm{H}_{\mathrm{if}}(\mathrm{s})+\mathrm{K}_{\mathrm{lff}} \mathrm{H}_{\mathrm{hf}}(\mathrm{s})\right\}
$$

Where, $\mathrm{K}$ is the controller overall gain . Subscripts If, if, hf stand for low-, intermediate- and high-frequency respectively. Each compensator contributing to $\mathrm{H}(\mathrm{s})$ is tuned to damp a specific frequency band. For each frequency band:

$$
\mathrm{H}_{\mathrm{jf}}(\mathrm{s})=\mathrm{H}_{\mathrm{jfl}}(\mathrm{s})-\mathrm{H}_{\mathrm{jf} 2}(\mathrm{~s}) \quad, \mathrm{j}=\mathrm{l}, \mathrm{i}, \mathrm{h}
$$

Previous extensive investigation revealed that for the SCG the time constants ratio is 50 for each control channel. Also, only one stage for each frequency band channel was found enough. Therefore, each controller stage takes the form :

$\mathrm{H}_{\mathrm{ji}}(\mathrm{s})=1+\mathrm{s} \mathrm{T}_{\mathrm{jf} 1} / 1+\mathrm{s} \mathrm{T}_{\mathrm{j} 2 \mathrm{2}}$
where, $\quad \mathrm{i} \quad$ is 1 and 2 for each frequency band.

$$
\mathrm{J}=\mathrm{l}, \mathrm{i} \text { and } \mathrm{f}
$$




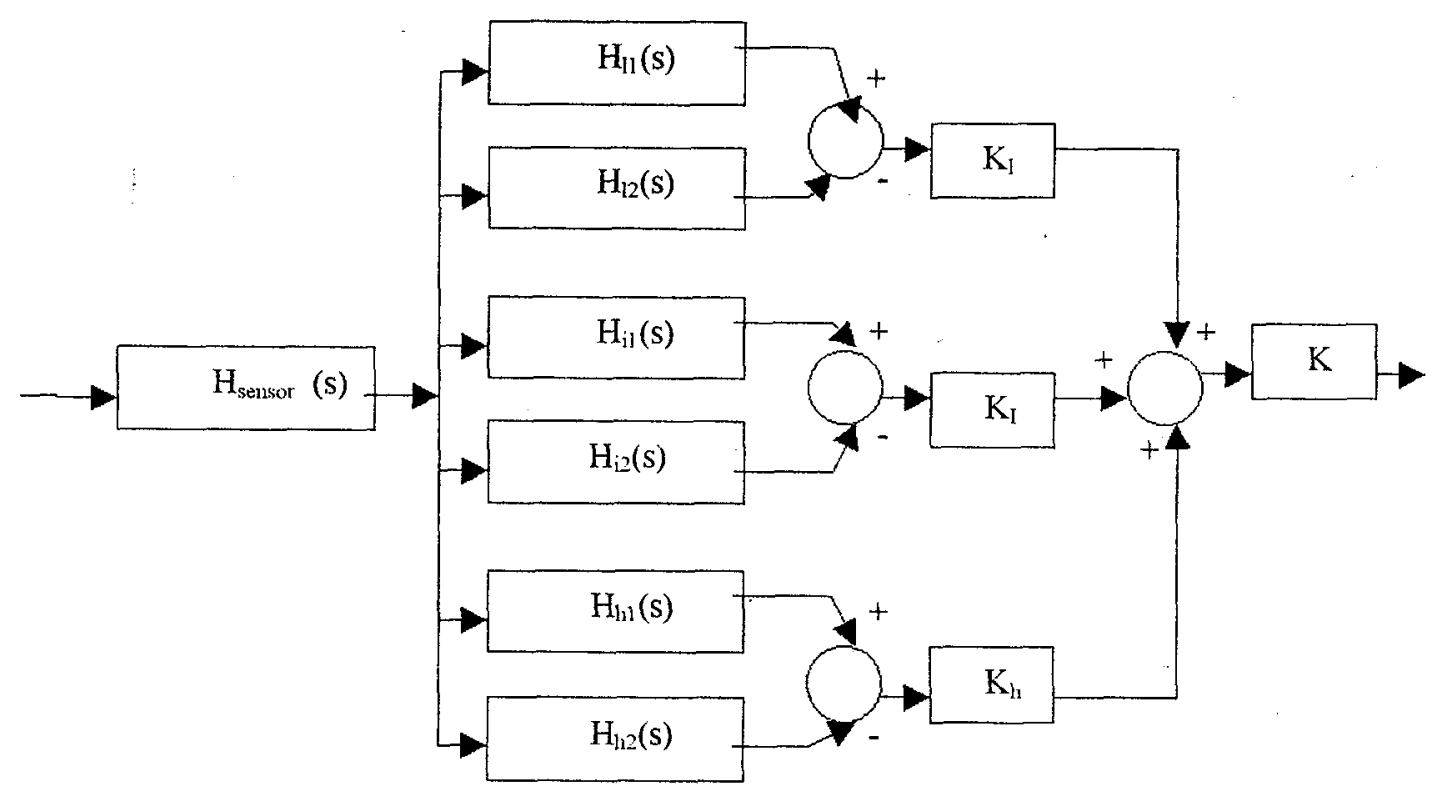

Fig. (2) Schematic diagram of the flexible controller

The state-space model of the controller is then :

$$
\begin{aligned}
\grave{Z} & =P Z+Q \omega \\
U & =K R Z
\end{aligned}
$$

where: $\mathrm{P}, \mathrm{Q}, \mathrm{R}$ depend on the time constants

$\omega$ is the controller input

$\mathrm{U}$ is the controller output

$$
\mathrm{K}=\left[\begin{array}{lll}
\mathrm{K}_{\mathrm{lf}} & \mathrm{K}_{\mathrm{if}} & \mathrm{K}_{\mathrm{hf}}
\end{array}\right]
$$

The non-linear model of the power system are perturbed about a steady state operating point. This provides the open -loop linearized system model as :

$$
\begin{gathered}
\dot{X}=\mathrm{AX}+\mathrm{BU} \\
\omega=\mathrm{C} X
\end{gathered}
$$

where, $\quad X$ is a state vector

$$
\begin{aligned}
& \mathrm{U} \text { is an input vector }=\left[\begin{array}{ll}
\mathrm{U}_{\mathrm{s}} & \mathrm{U}_{\mathrm{ref}}
\end{array}\right]^{\mathrm{T}} \\
& \mathrm{U}_{\mathrm{c}} \text { is the input from the controller } \\
& \mathrm{U}_{\mathrm{ref}} \text { is the reference voltage input } \\
& \omega \text { is the speed output }
\end{aligned}
$$

The control problem is to determine a matrix $\mathrm{K}$ so that the output oscillations of the closed loop system will be damped out when a perturbation occurs. Then the closed loop system state space model is :

$$
\dot{X}_{c}=A_{c} X_{c}+B_{c} U
$$




$$
\begin{aligned}
& \omega=C_{c} X_{c} \\
& A_{c}=\left[\begin{array}{cc}
A & B K R \\
Q C & P
\end{array}\right] \quad, \quad B_{c}=\left[\begin{array}{c}
B \\
0
\end{array}\right] \quad \& \quad C_{c}=\left[\begin{array}{ll}
C & 0
\end{array}\right]
\end{aligned}
$$

The modal performance measure $\mathrm{J}$, for the closed loop system equations (8), (9) and (10) is defind as [12]:

$$
\mathrm{J}=\sum_{i=1}^{N}\left\{\left(\mathrm{X}_{\mathrm{o}}^{\mathrm{T}} \mathrm{V}_{\mathrm{i}}^{\mathrm{T}}\right) \mathrm{U}_{\mathrm{i}}^{\mathrm{T}} \mathrm{M}_{\mathrm{i}} \mathrm{U}_{\mathrm{i}}^{*}\left(\mathrm{~V}_{\mathrm{i}}^{*} \mathrm{X}_{\mathrm{o}}\right) \Psi\left(\sigma_{\mathrm{i}}, \omega_{\mathrm{i}}\right)\right\}
$$

where: $N$ is the order of the closed loop state matrix $A_{c}$,

$\mathrm{U}_{\mathrm{i}}, \mathrm{V}_{\mathrm{i}}$ are right and left eigen vectors corresponding to the $\mathrm{ith}$ mode

()$^{\mathrm{T}},()^{*}$ are the matrix transpose and complex conjugate,

$X_{0} \quad$ is the initial state of the closed loop system,

$\Psi\left(\sigma_{i}, \omega_{i}\right)$ is a function of the $I \underline{\text { th }}$ mode $\lambda_{i}=\sigma_{i} \pm \omega_{i}$,

$\zeta_{i} \quad=-\sigma_{i} / \sqrt{ } \sigma_{i}^{2}+\omega_{i}^{2}$ is the damping ratio of the $i$ th mode.

The optimization algorithm used in [12] is implemented, with a linear convergence rate, then the values of the controller gains are obtained.

The controller gains and time constants are given in the appendix.

\section{4-EIGEN VALUES ANALYSIS:}

Using the time -invariant state space model, a conventional PI controller is designed as well as the flexible controller. The eigenvalues are obtained for the system as shown in Table 1. These results show that the damping ratios of the oscillation modes are greatly improved with the use of the flexible controller.

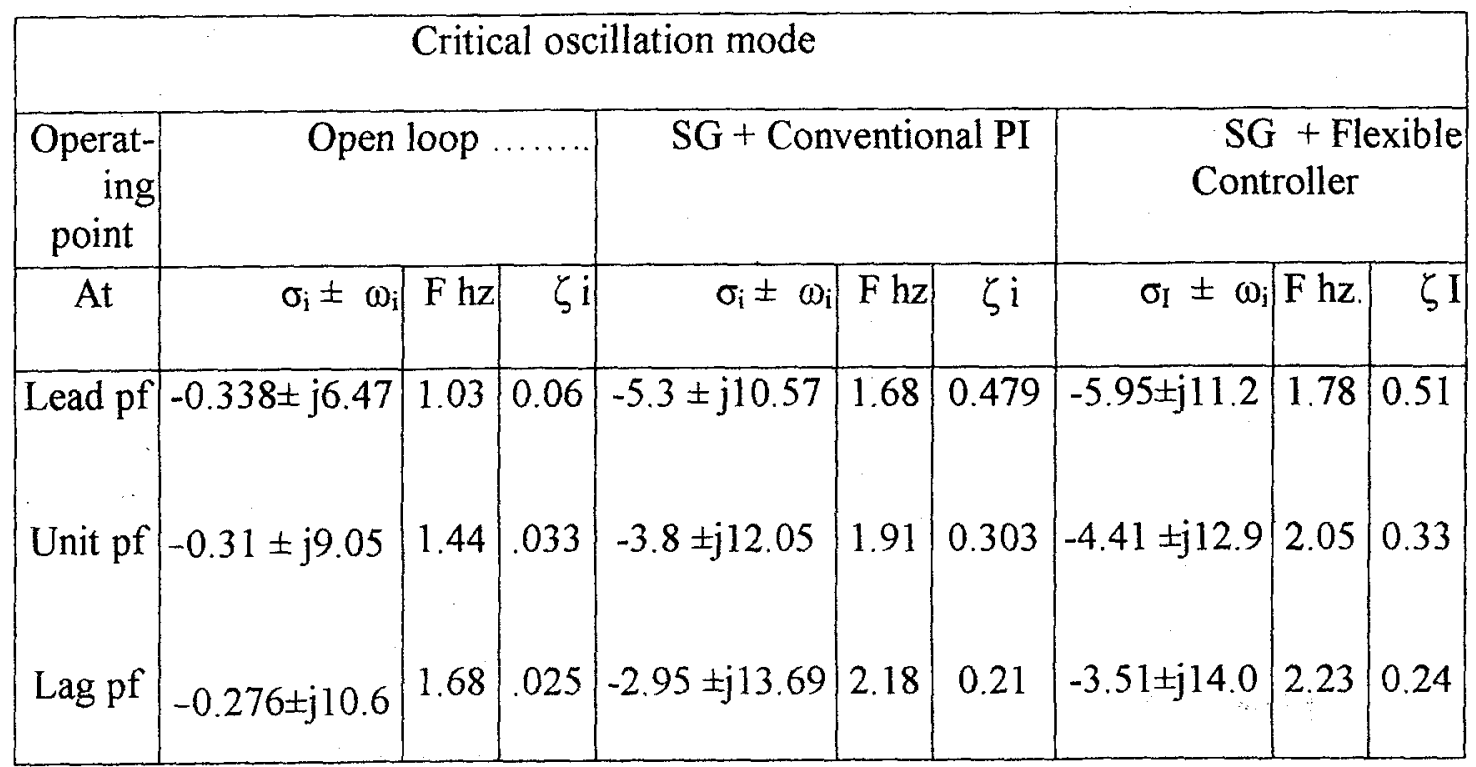

\section{Table 1}




\section{5-SIMULATION RESULTS AND DISCUSSIONS}

To indicate the effectiveness of the proposed flexible controller, results simulation for the system are obtained under different operating conditions and the modal performance measure was evaluated in response to a $120 \mathrm{~ms}$ duration short circuit at the transformer high voltage side. The system detailed non-linear equations including all control loops are solved by using the Rung-Kutta technique. Figures (3) to (5) depicts the system performance in case of three-phase short circuit fault with the proposed controller for different operating conditions. The simulation results illustrate that the proposed controller achieve a significant improvement in the system behavior, a considerable reduction in the valve movements and a high damping to the rotor oscillations. The results thus demonstrate clearly the effectiveness of the proposed scheme in damping the system oscillations and improving its performance.

\section{6- CONCLUSIONS}

The paper described a new proposed flexible controller to enhance the performance and extend the stability limits of SCGs. The proposed scheme is validated and verified via eigenvalues analysis and simulated non-linear time response of the new controller in comparison with other control systems. It is clear that the new strategy is significant in damping the system oscillations and enhancing its dynamic performance for a wide range of operating conditions. The system behavior with the proposed control scheme is compared with the behavior when it's equipped with speed governor accompanied with proportional plus integral controller. The paper demonstrated that the proposed controller can provide significant performance improvements to power system oscillations and can be a useful substitute to other conventional schemes, in damping the system low frequency oscillations.

\section{REFERENCES}

(1) R. Grondin, L. Kamawa, L. Soulieres, J. Potvin, R. Champagne," An approach to PSS design for transient stability Improvement through supplementary damping of the common low-frequency", IEEE Trans., PWRs-8(3), August 1993,pp. 954-963.

(2) E. Zhou, O. P. Malik, G. S. Hope,"Theory and method for selection of power System stabilizer design", IEEE Trans., EC-6(1), March 1991, pp.170-176.

(3) IEEE special stability control working group, "Static Var compensator models For power flow and dynamic performance simulation,"'IEEE Trans., PWRS-9(1), February 1994, pp.229-240.

(4) P. Kundur, M. Klein, G.j. Rogers, M.S. Zywno,"Application of power system Stabilizers for enhancement of overall system stability", IEEE Trans., PWRS-4(2), May 1989, pp. 614-628.

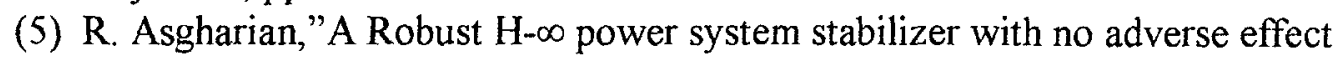
on shaft torsional modes",Paper 94 WM 125-5 EC, IEEE/PES 1994 Winter Meeting, New York, Jan.30-Feb.3,1994.

(6) M. Klein, L. X. Le, et al," $\mathrm{H}-\infty$ damping controller design in large power Systems", IEEE Trans., PWRS-10(10, February 1995, pp. 158,166. 
(7) Z. Ao, T. S. Sidhu, R.J. Fleming," Stability investigation of a longitudinal power system and its stabilization by a coordinated application of power system stabilizers" , Paper 94 WM 128-9 EC, IEEE/PES 1994 Winter Meeting, New. York, Jan. 30-Feb. 3, 1994.

(8) J. Chow, J.J. sanchez-Gascu,'Pole-Placement design of power system stabilizers, IEEE Trans. PWRs-4(1), February 1989, pp.271-277.

(9) I. Kamwa, G. trudle, L. Gurrin-Lajoie,"Low-order black box Models for control systems design in large power systems", Paper presented at PICA'95, Salt Lake, City, May 7-12 1995.

(10)G.A. Morsy, H. Khattab , A. M. Kinawy,"Design of a PI controller for a superconducting generator", Eng. Research Blue., Vol. 23, No. 1, Fac. Of Eng., Men. Univ., Jan 2000, pp. 61-77.

(11)G. A. Morsy, T. A. Mohammed,"An ANN based PI controller for a superconducting generator", ", Eng. Research Blue., Vol. 24, No. 3, Fac. Of Eng., Men., Univ., July 2001, pp.113-125.

(12)J. B. Simo, I. Kamwa, G. Trudel, S. A. Tahan," Validation of a new modal performance measure for flexible controllers design", IEEE Trans. PWRs-11(2), May 1996, pp. 819-826.

\section{APPENDIX}

\section{A- THE STATE EQUATIONS REPRESENTED THE POWER SYSTEM ARE}

$$
\begin{aligned}
& p \psi_{f}=\omega_{o}\left(V_{f}-i f R_{f}\right) \\
& p \psi_{d}=\omega_{o}\left(V_{d}+i_{d}\left(R_{a}+R_{e}\right)+\psi_{q}\right)+\omega \psi_{q} \\
& p \psi_{q}=\omega_{o}\left(V_{q}+i_{q}\left(R_{a}+R_{e}\right)-\psi_{d}\right)-\omega \psi_{d} \\
& p \psi_{D I}=-\omega_{o} i_{D I} R_{D I} \\
& p \psi_{Q I}=-\omega_{o} i_{Q 1} R_{Q 1} \\
& p \psi_{D 2}=-\omega_{o} i_{D 2} R_{D 2} \\
& p \psi_{Q 2}=-\omega_{o} i_{Q 2} R_{Q 2} \\
& p \delta=\omega \\
& \mathrm{p} \omega=\frac{\omega_{o}}{2 \mathrm{H}}\left(\mathrm{T}_{\mathrm{m}}-\mathrm{T}_{\mathrm{e}}\right) \\
& T_{e}=\psi_{d} i_{q}-\psi_{q} i_{d}
\end{aligned}
$$

The transmission system is includeed in the model, replacing $R_{a}$ by $\left(R_{a}+R_{e}\right)$ and $X_{d}$ and $X_{q}$ by $\left(X_{d}+X_{e}\right)$ and $\left(X_{q}+X_{e}\right)$ respectively.

The model of the three-stage steam turbine with reheat and the electro-hydraulic governor considered in this study follows the IEEE standard representation and the special IEEE recommendations for the turbine of the SCG. Their state equations may be written as:

$$
\begin{aligned}
& p Y_{H P}=\left(G_{M} P_{o} \cdots Y_{H P}\right) T_{H P} \\
& p Y_{R P}=\left(Y_{H P}-Y_{R H}\right) / T_{R H} \\
& p Y_{I P}=\left(G_{I} Y_{R H}-Y_{l P}\right) T_{I P} \\
& p Y_{L P}=\left(G_{l P} \cdots Y_{L P}\right) / T_{L P} \\
& T_{m}=F_{H P} Y_{H P}+F_{I P} Y_{I P}+F_{L P} Y_{L P}
\end{aligned}
$$


The electro-hydraulic governor equations are :

$p G_{M}=\left(U_{G M}-G_{M}\right) / T_{G M}$

$p G_{l}=\left(U_{G l}-G_{l}\right) / T_{G l}$

Where the position and rate limits are,

$0 \leq G_{M}, G_{l} \leq 1.0$ and $-6.7 \leq p G_{M}, p G_{l} \leq 6.7 \mathrm{p} . \mathrm{u} / \mathrm{sec}$

\section{B -THE SYSTM PARAMETERS}

- SCG parameters

2000 MVA, $1700 \mathrm{MW}, 3000 \mathrm{rpm}$

$\mathrm{X}_{\mathrm{d}}=\mathrm{X}_{\mathrm{q}}=0.453$ p.u., $\mathrm{X}_{\mathrm{f}}=0.541$ p.u.

$X_{\mathrm{KD} 1}=X_{\mathrm{KQ} 1}=0.2567$ p.u. $\quad \mathrm{X}_{\mathrm{FKD} 2}=0.3398$ p.u.

$\mathrm{X}_{\mathrm{af}}=\mathrm{X}_{\mathrm{fKD} 1}=\mathrm{X}_{\mathrm{adl}}=\mathrm{X}_{\mathrm{ad} 2}=\mathrm{X}_{\mathrm{KD} 1 \mathrm{KD} 2}=0.237$ p.u.

$\mathrm{X}_{\mathrm{aq} 1}=\mathrm{X}_{\mathrm{aq} 2}=\mathrm{X}_{\mathrm{KQ} 1} \mathrm{~K}_{\mathrm{Q} 2}=0.237$ p.u.

$\mathrm{R}_{\mathrm{KD1}}=\mathrm{R}_{\mathrm{KQ1}}=0.01008$ p.u.

$\mathrm{R}_{\mathrm{a}}=0.003, \quad \mathrm{R}_{\mathrm{KD} 2}=\mathrm{R}_{\mathrm{KQ} 2}=0.00134$,

$\mathrm{H}=3 \mathrm{KWS} / \mathrm{KVA}$

Transmission System Parameters

$X_{T}=0.15$ p.u. $\quad, \quad R_{T}=0.0003$ p.u.

$X_{L}=0.05$ p.u. $\quad, \quad R_{L}=0.005$ p.u.

- Parameters of Governor and Turbine

$\begin{array}{llll}T_{H P}=0.1 \mathrm{sec} . & , & F_{H P}=0.26, & T_{I P}=0.3 \mathrm{sec} . \\ F_{I . P}=0.3 \mathrm{sec} & , & F_{L . P}=0.32 & T_{R H}=10 \mathrm{sec} . \\ T_{G M}=T_{G .1}=0.1 \mathrm{sec} . & , & P_{o}=1.2 \mathrm{p} . \mathrm{u} . & \end{array}$

- Parameters of Flexible Controller

$\begin{array}{llll}\mathrm{T}_{11}=0.01 \mathrm{sec} . & , & \mathrm{T}_{12}=0.5 \mathrm{sec} & \mathrm{T}_{\mathrm{i} 1}=0.008 \mathrm{sec} . \\ \mathrm{T}_{\mathrm{i} 2}=0.4 \mathrm{sec} & , & \mathrm{T}_{\mathrm{h} 1}=0.004 \mathrm{sec} & \mathrm{T}_{\mathrm{H} 2}=0.2 \mathrm{sec} . \\ \mathrm{K}_{\text {If }}=0.1, & , & \mathrm{~K}_{\mathrm{if}}=0.02 & \mathrm{~K}_{\mathrm{hf}}=0.05\end{array}$

\section{Nomenclature}

$\mathrm{H}$ Inertia constant (kWs/kVA)

I Current (p.u.)

$\mathrm{P} \quad$ Differential operator

R Resistance (p.u.)

T Torque

$\mathrm{V}$ Voltage (p.u.)

X Reactance (p.u.)

\section{Greek letters}

$\delta$ Rotor angle

$\psi \quad$ Flux linkage (p.u.)

$\omega$ Angular speed ( $\mathrm{rad} / \mathrm{s})$ 


$\begin{array}{ll}\text { Subscripts } & \\ \mathrm{a} & \text { Armature } \\ \mathrm{q} & \mathrm{d} \text { and q componenets of stator winding } \\ \mathrm{e}, \mathrm{M} & \text { Electrical, mechanical } \\ \mathrm{f} & \text { Field } \\ \mathrm{o} & \text { Steady state } \\ \mathrm{FKD} & \mathrm{d} \text { and q mutual components between outer screen and field } \\ \mathrm{fKQ} & \text { winding SCG } \\ \mathrm{FKD}_{2}, \mathrm{fQ} & \text { d and q mutual components between inner screen and field } \\ \mathrm{KD}_{1}, \mathrm{KQ}_{1} & \text { winding SCG } \\ \mathrm{KD}_{2}, \mathrm{KQ}_{2} & \text { d and q componenets of outer screen } \\ & \text { d and q components of inner screen }\end{array}$



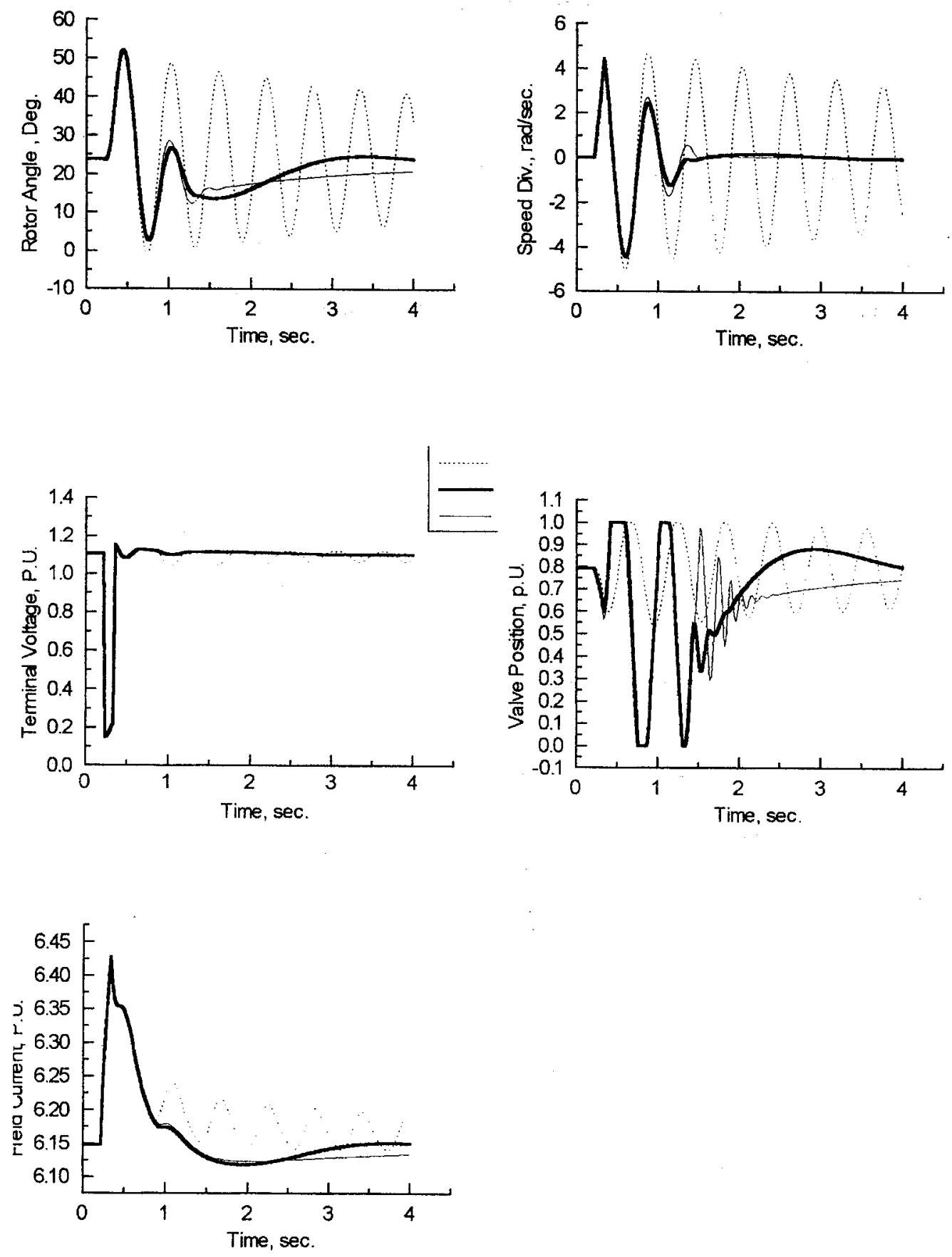

Fig.(3)Transient response of a SCG to a 3-phase s. c. (lag power factor)

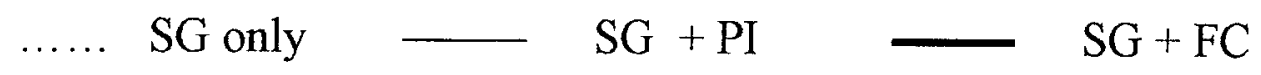



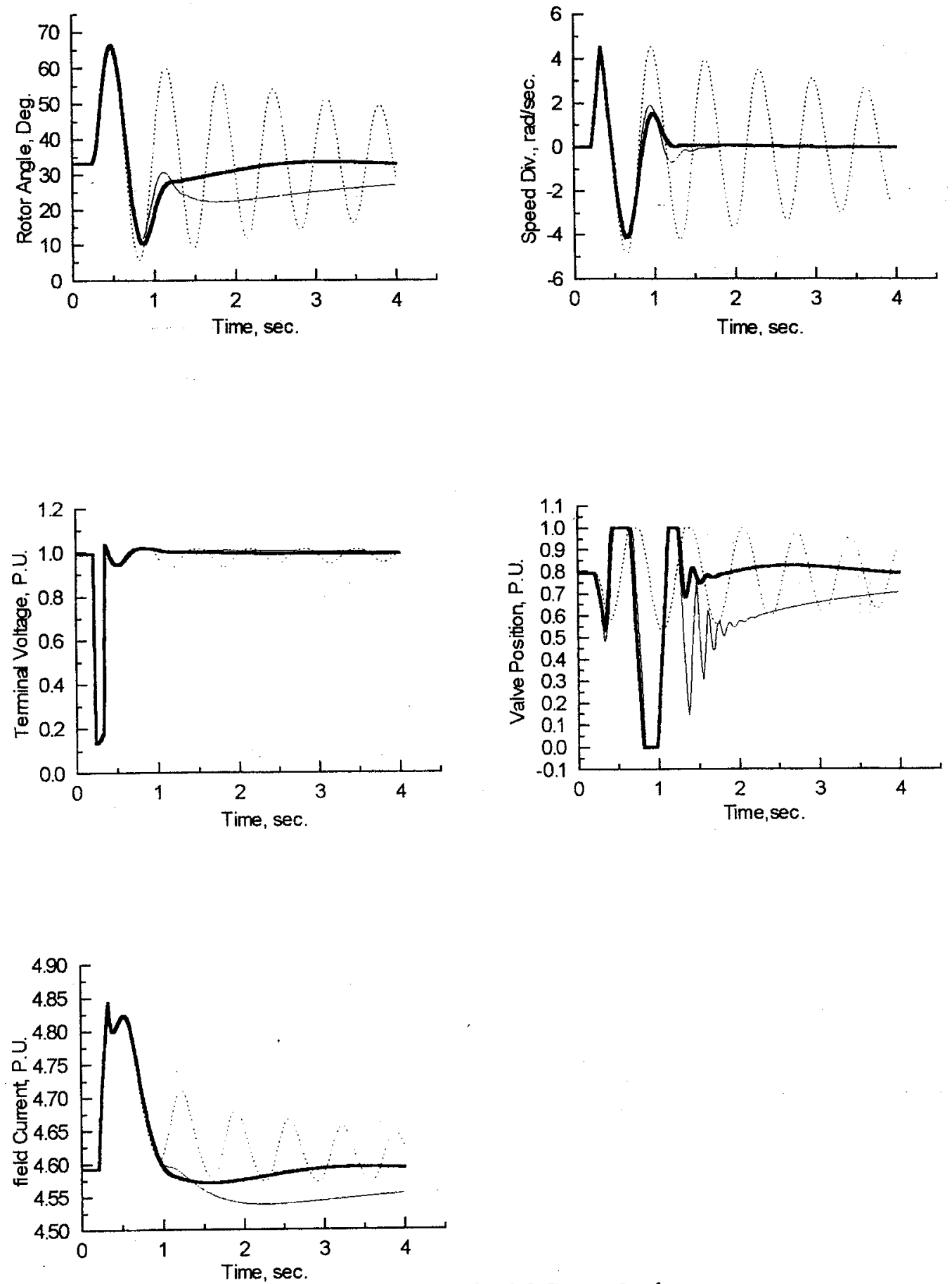

Fig.(4) Transient response of a SCG to a 3-phase s. c.

(unity power factor)

SG only

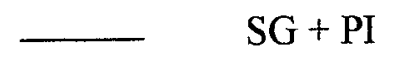

- $\mathrm{SG}+\mathrm{FC}$ 

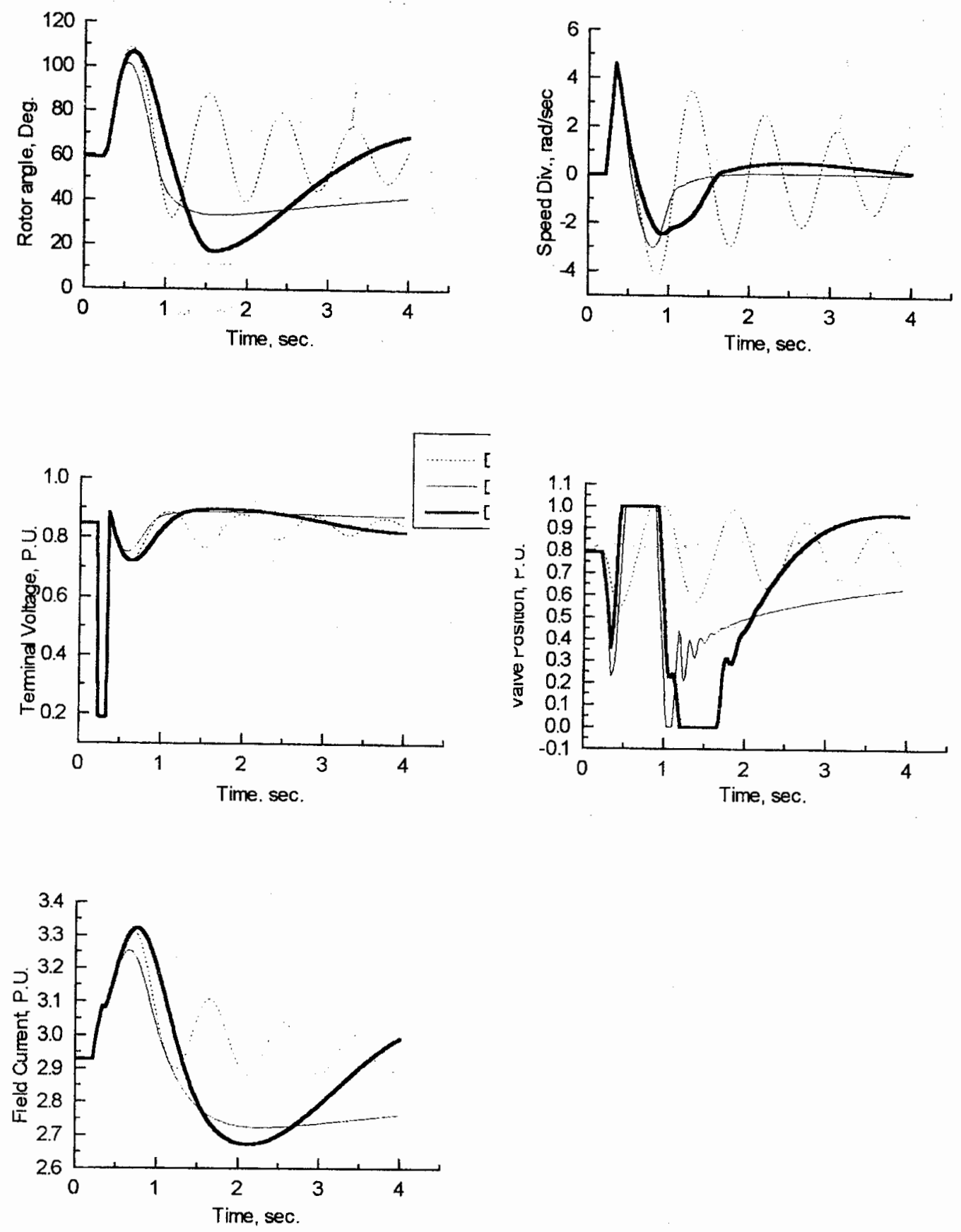

Fig.(5) Transient response of a SCG to a 3-phase s. c.

(lead power factor)

SG only $\quad \mathrm{SG}+\mathrm{PI} \quad-\quad \mathrm{SG}+\mathrm{FC}$ 
تصميم وتحقيق استخدام حاكم مرن قوى لآلة فائقة التوصيل

$$
\text { د إل مال عبد الوهاب مرسى }
$$

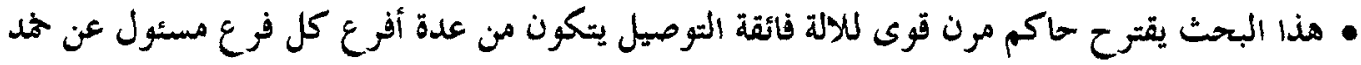

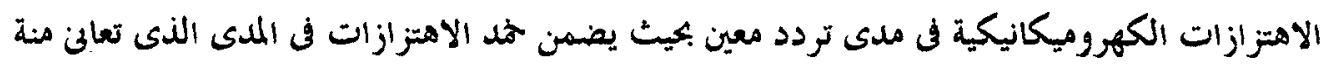

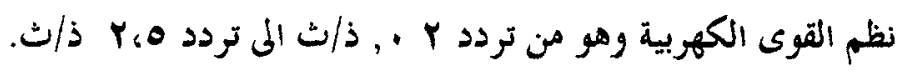

• تم تصميم الحاكم الجلديد باختيار افضل البلرامترات optimization التى تضمن الوصول المى انسب

$$
\text { وافضل مقياس اداء }
$$

• باستخدام نموزج خطى لنظام القوى المتضمن للالة الفائقة تح حساب القيم المميزة للنظام عند ظروف

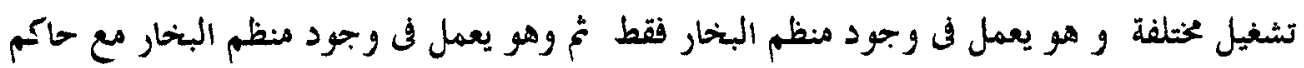

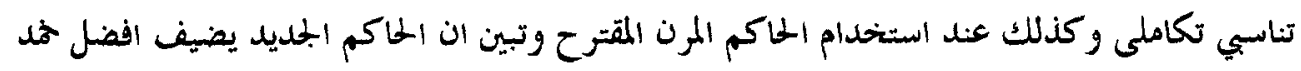
موجب للأوضاع الحر جة مما يوضح تميزة عن الأنواع السابقة.

• تم تطبيق الحاكم المجديد مع النموزج غير المططى النفصيلى للنظام وبدراسة اداء النظام عند ظروف تشغيل

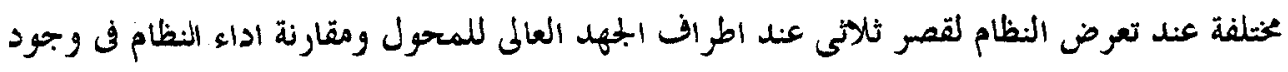

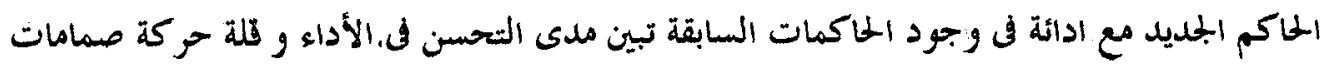

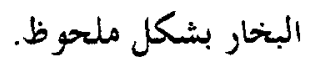

